\title{
Virtual Occupant Model for Riding Comfort Simulation
}

\author{
Hyung Yun Choi ${ }^{1}$ Manyong Han ${ }^{1}$ Akinari Hirao ${ }^{2}$ Hisayoshi Matsuoka ${ }^{2}$ \\ ${ }^{1}$ Hongik University, Korea, hychoi@ hongik.ac.kr, myhan@mail.hongik.ac.kr \\ ${ }^{2}$ Nissan Motor Co. Ltd, Japan, a-hirao, hisayoshi_m@mail.nissan.co.jp
}

\begin{abstract}
A digital human body model as a virtual occupant surrogate for the riding comfort simulation is developed for both 1D lumped network (Modelica) and 3D mesh based (Finite Element) solutions. Since the composition of 1D and 3D versions of the human body model has a similar multibody system architecture, the kinematic responses from both solutions are almost equivalent. The models are therefore complementary, since the economic 1D models can serve effectively in design exploration and optimization, while their sophisticated 3D counterparts can serve in final design validation. The detailed modeling process and validation results against standard seat vibration excitation test are introduced in this paper, preparing the models for use in seat design.
\end{abstract}

Keywords: digital human body model, riding comfort simulation, ID lumped network Modelica model, 3D mesh based Finite Element model, vibration excitation

\section{Introduction}

A virtual human body model (VHBM) is developed for quantitative and objective assessments of the riding comfort design of vehicles. The VHBM has biofidelic dynamic characteristics of human occupants during the vehicle ride. The anthropometry of the finite element human body model is based on a previous study [Kim 2007] and represents a standard North American $50^{\text {th }} \%$ tile male from the SizeUSA population survey 2000-03.

There have been many CAE studies to virtually simulate static and dynamic interactions between the human occupant and the vehicle seat. Montmayeur et al [Montmayeur 2004] used a human body model to predict the sitting pressure distribution and head-to-seat vertical transmissibility. There was a good correlation against the experiment but the position of the human body model was limited to upright erect sitting without a back support. Choi et al [Choi 2008] used a human body model to evaluate lumbar support design. They investigated postural changes of sitting occupants such as seat back pressure distribution and lordotic curvatures of the lumbar spine with the different configurations of lumbar support, and the prominence and height of the support. Yamada et al [Yamada 2016] used the THUMS model (Total Human Model for Safety, version 5) to investigate the influence of muscular strength and seat reaction force on occupant kinematics in single lane change maneuvers. It was found that some skeletal muscles in the THUMS model were needed to activate, e.g., $350 \mathrm{~N}$ by abdominal oblique muscles to resist against 1.0G lateral vehicle motion. Han et al [Han 2016] presented an efficient way to model muscle forces of vehicle occupants as they maintain the postural stability during the ride. The active joint torque controlled by a proportional integral derivative (PID) closed loop was introduced at the elbow joint to simulate voluntary and reflexive response of the human subjects.

The main focus of the VHBM in this paper is showing its capability of not sophisticated but quite effective representations of active skeletal muscle forces by developing PID-controlled active torques at articulated joints. It is hypothesized that vehicle occupants brace their limbs and trunk to maintain the initial upright (comfortable) sitting posture. Accordingly, the VHBM model autonomously develops the skeletal muscle forces, i.e. active torques, at articulated joints against the external perturbations.

The VHBM was built for two kinds of solution, 1D lumped network (Modelica) and 3D mesh based (Finite Element) solutions. The 1D lumped network solution is very effective for the multi physical system with many controllers. It is also suitable for the calculation of large numbers of variants. On the other hand, the 3D mesh based solution with its fine geometry and material properties can provide detailed interactions with the neighboring structure, the vehicle seat in our case. However the 3D solution requires a great deal of computing power due to its high level of modeling complexity. The topological composition of the 1D version of the human body model is the same as that of the $3 \mathrm{D}$ version since they are both based on a multibody system with PID controllers. The outcomes of two different solutions, e.g., dynamic response of human body model to external loadings, are thus almost identical. Therefore, the use of the 1D model to calibrate intrinsic and extrinsic parameters of the human body model, such as joint properties and weighting factors (gains) in the PID controllers, is quite beneficial. An optimization process is normally adopted for determining those modeling parameters, which becomes an extremely lengthy task when a 3D model is used. In case with the Genetic Algorithm at the optimization process, a number of around several hundred model runs (15 generations X 50 populations) are often necessary for the convergent result. However the 3D human body model is also necessary at the practical application stage 
because it produces many informative outcomes at the riding comfort simulation, e.g., dynamic sitting pressure distribution.

\section{Human Body Modeling}

\subsection{Multibody Modeling}

The whole human body are segmented into 15 body regions (see Fig. 1), i.e., head, neck, upper/center/lower trunks, left and right upper/lower arms, left and right upper/lower legs, and left and right foot. And they are articulated by 14 joints as listed in Table 1 . The dynamic properties of the 15 body segments modeled as rigid bodies: mass, center of gravity, and 2nd mass moment of inertia of each body region, are calculated by GEBOD program [Cheng 1996]. The averaged values of 32 body dimensions measured from 10 test subjects of this study are used as input parameters at the GEBOD calculation. Kinematic joint elements are used for the articulation of the 15 body segments of which the main biomechanical characteristics are defined by stiffness and damping coefficients. The kinematic joint element describes the passive characteristics of the human joint, together with, the active torques. Assuming that a co-contraction of agonist and antagonist muscles stiffens the joint articulation, the damping coefficients of the passive kinematic joint element are adjusted for the different levels of pre-tensions, which is considered as a major mechanism of voluntary muscle activation. Meanwhile, the spring constant of the kinematic joint element represents the inter-subject variation of the muscular structure, e.g., male versus female, younger versus older.

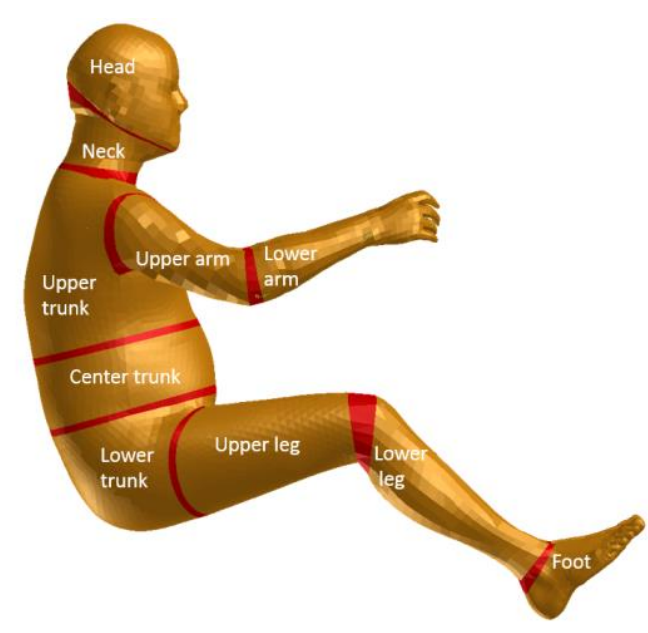

Figure 1. Whole body model segmented by 15 rigid bodies and 14 articulated joints (in 3D FE model view)

Table 1. Fourteen articulated joints with their anatomical positions

\begin{tabular}{|c|c|c|c|}
\hline$\#$ & Articulated joint & DOF & Anatomical position \\
\hline 1 & Head-neck & 3 & OC joint \\
\hline 2 & Neck-Upper trunk & 3 & sC7/T1 \\
\hline 3 & Upper-Center trunk & 3 & T12/L1 \\
\hline 4 & Center-Lower trunk & 3 & L5/S1 \\
\hline 5,6 & Upper trunk-arm, R, L & 3 & Right, Left shoulders \\
\hline 7,8 & Upper-Lower arm, R, L & 1 & Right, Left elbows \\
\hline 9,10 & Lower trunk-leg, R, L & 3 & Right, Left hip joints \\
\hline 11,12 & Upper-Lower leg, R, L & 1 & Right, Left Knees \\
\hline 13,14 & Lower leg-foot, R, L & 3 & Right, Left ankle \\
\hline
\end{tabular}

\subsection{Wobbling Masses}

The internal organs in the ventral body cavity, such as lungs, heart, stomach, intestines, liver, spleen, kidneys, and bladder, are classified by their anatomical locations, either above or below the diaphragm, i.e., in thoracic and abdominal/pelvic cavities, respectively. The organs in a same or adjacent cavity are grouped together as a single lumped mass in the virtual occupant model, Fig. 2 . The wobbling behavior of the internal organs at whole body vibration is thus characterized by two lumped masses, one for the thoracic cavity and the other one for the abdominal and pelvic cavities. Each wobbling mass was estimated respectively as $5 \mathrm{~kg}$ and $10 \mathrm{~kg}$ for the thoracic and abdominal/pelvic masses.

All sides of the two wobbling masses are tied by elastic spring elements to the inner surfaces of the thoracic and abdominal cavities. There are also elastic spring elements between two wobbling masses connecting the bottom side of thoracic mass and the top side of abdominal/pelvic mass. The mechanical characteristics of spring elements such as stiffness and damping coefficients were assigned to reproduce the biofidelic dynamic behavior of the two wobbling masses.
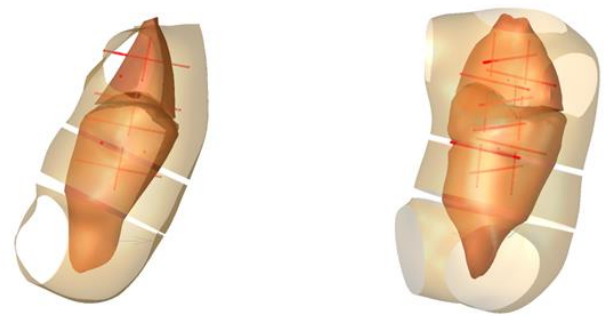

Figure 2. Wobbling masses in the trunk (in 1D SimulationX model view) 


\subsection{Active Joint Torque with PID Close Loop Control}

Voluntary and reflexive muscle activation of a vehicle occupant is modeled by active joint elements at each anatomical joint position (e.g., shoulder, knee, spine, etc.). There are two basic elements at each joint, i.e., the passive kinematic joint element and the torque actuator. Contrastively to voluntary activation of individual muscles, i.e., the pre-tension and consequent stiffening of the articulated joint represented by the passive kinematic joint element, a vestibular reflexive muscle activation for the posture stabilization is modeled by the introduction of active torques with PID closed loop control. As an example, the modeling of the head-neck joint $(\mathrm{C} 0-\mathrm{C} 1)$ is shown in Fig. 3. The active torque, the control signal, is a sum of proportional, integral, and derivative terms between the current and the reference (initial) joint angles. The gain values at the PID control determine the rates of torque generation. Faster torque generation with larger gain values stands for the prerecognition of the upcoming external perturbation. Each term at PID can be adjusted to calibrate the rate of muscle recruitment for fine control of the reflexive response of the human occupant. Authors of this paper showed a successful application of the proposing active joint modeling with the elbow reacting to the jerk loading [Choi 2016, Han 2016].

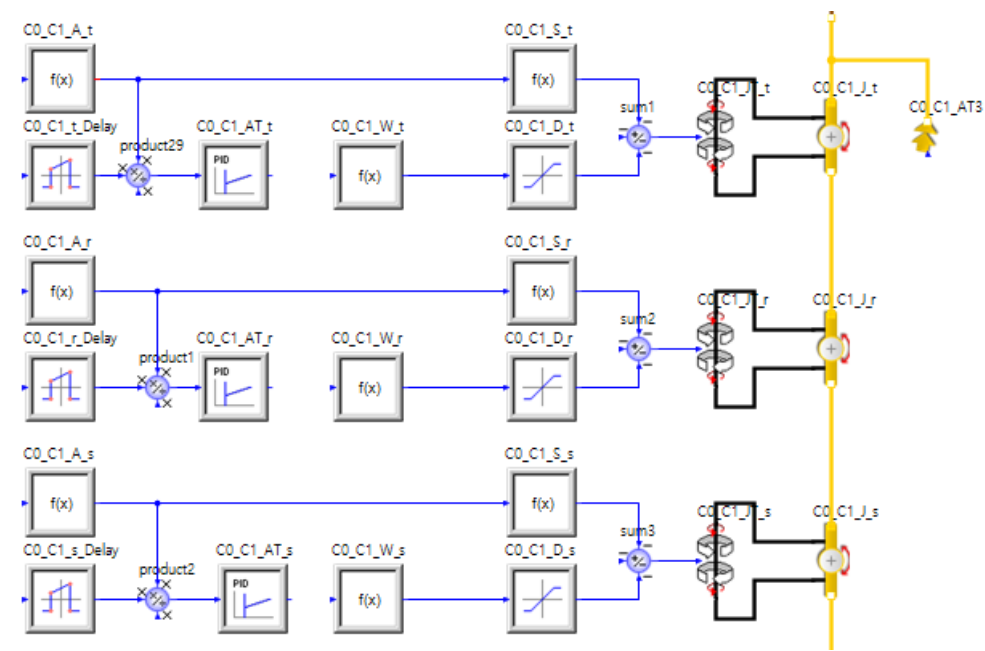

Figure 3. Block diagram of head-neck joint (C0-C1) with active torque using PID close loop control (in 1D model view)

\subsection{Finite element model vs. Modelica model}

The composition of 1D lumped network (Modelica) version and 3D mesh based (Finite Element) version of the whole body model in Fig. 4 has similar multibody system architecture. The same segmental dynamic properties, joint characteristics, and PID control gains, are assigned to both 1D and 3D models. Consequently, the outcomes such as dynamic responses from both models to external loadings are almost identical. So, utilizing the computational efficiency of 1D Modelica model and solution instead of 3D FE model, the calibration process of the intrinsic and extrinsic modeling parameters become much faster.

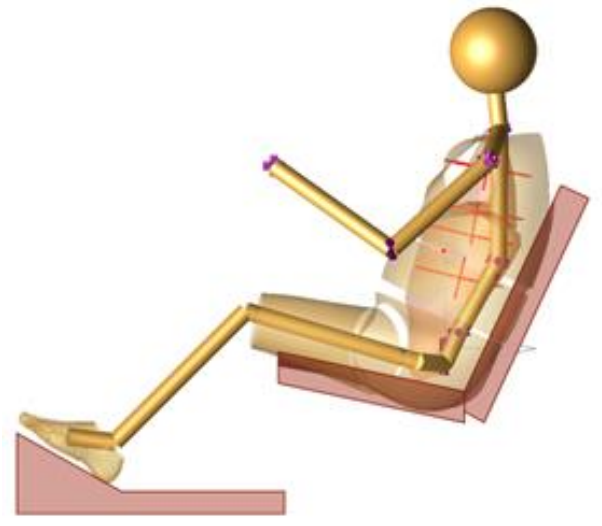

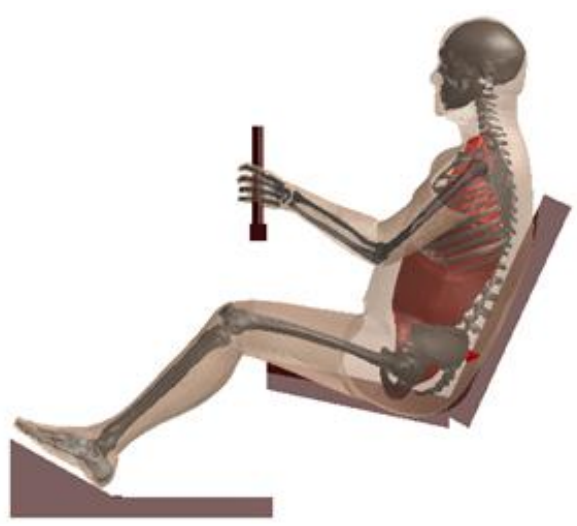

Figure 4. 1D lumped network (top) and 3D finite element (bottom) whole body human models.

The one of lacking feature at the 1D lumped network solution compared to the 3D mesh based solution is the pragmatic sliding contact algorithm to handle the nonlinear boundary conditions. In the context of riding comfort simulation, the main application of the occupant model, a dynamic interaction between the occupant and the vehicle seat, is the most relevant case. In general, a riding comfort design of the vehicle seat is responsible for the quality of static support at a sitting posture and the dynamic isolation against floor level 
vibration. The measurement of the sitting body pressure distribution and its pattern analysis provide the design assessment of the static support, while the body regional transmissibility characterizes the dynamic isolation of the excitation vibration. There are model libraries available at SimulationX to handle the sliding contact between objects, such as polygon-polygon contact. The polygon-polygon contact library computes the penalty contact force based on the amount of overlapping depth between two-dimensional cross sectional outline polygons of objects. This is a suboptimal choice at 1D solutions but an appropriate selection of cross section and contact parameters is always required to reproduce the same outcome from the sliding contact in 3D mesh based solutions. Fig. 5 shows a polygon-polygon contact definition between buttock and seat at the 1D model.

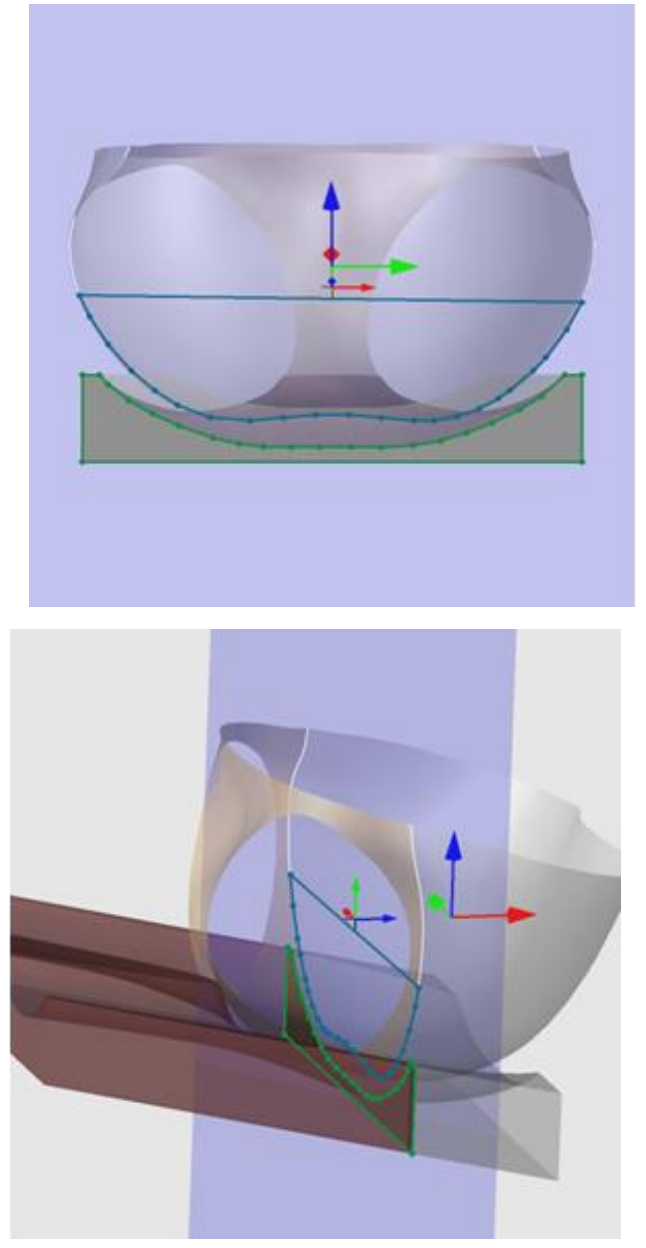

Figure 5. 2D polygon-polygon contact at 1D lumped network models.

In addition, the 3D FE whole body model has deformable flesh layers modeled by a visco-elastic Ogden rubber material of solid element at those body regions, i.e., dorsal back, buttock and thigh, which are normally in touch with vehicle seat. (Fig. 6) This deformable flesh layer can simulate the precise distribution of dynamic sitting pressure, which is hardly obtainable from the 1D lumped network solution.

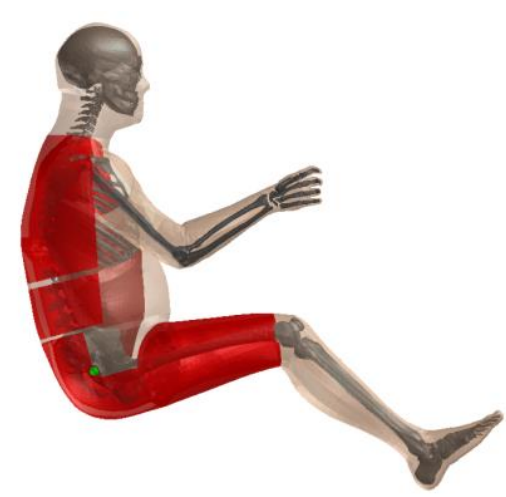

Figure 6. Deformable flesh layer in 3D FE model

The comparison of computation times between three models, two 3D finite element models with and without flesh layer and 1D Modelica model is listed in Table 2.

Table 2. Simulation time of a loading case (X direction excitation, $5 \mathrm{~Hz}, 0.2 \mathrm{~g}$ relaxed condition for $4 \mathrm{sec}$ )

\begin{tabular}{|c|c|c|}
\hline Model & $\begin{array}{c}1 \text { core } C P U^{*} \\
\text { time }(\mathrm{sec})\end{array}$ & $\begin{array}{c}\text { 8 core CPU } \\
\text { time }(\mathrm{sec})\end{array}$ \\
\hline 3D FE with flesh & $\begin{array}{c}108,900 \mathrm{sec} \\
(30.3 \text { hours })\end{array}$ & $\begin{array}{c}14,770 \mathrm{sec} \\
(4.1 \text { hours })\end{array}$ \\
\hline 3D FE w/o flesh & $\begin{array}{c}13,880 \mathrm{sec} \\
(3.9 \text { hours })\end{array}$ & $\begin{array}{c}1,980 \mathrm{sec} \\
(0.6 \text { hours })\end{array}$ \\
\hline 1D Modelica & $\begin{array}{c}1,851 \mathrm{sec} \\
(0.5 \text { hours })\end{array}$ & NA \\
\hline
\end{tabular}

* CPU processor: $17-4770 \mathrm{~K} 3.5 \mathrm{GHz}$,

\section{Validation of Human Body Model against Vibration Excitation Test}

\subsection{Excitation Vibration Test}

A total of ten male subjects with standard North American $50^{\text {th }} \%$ tile anatomies between 35 and 45 years old were recruited. The same selection process of test subjects is adopted from the previous study [Kim 2007]. From the statistical factor analysis of the study, six primary dimensions listed in Table 3 were chosen to represent the overall body shape and size of the target population. Based on the SizeUSA survey (2000-03), the specific ranges (average $\pm \sigma / 4$ ) in Table 3 for $50^{\text {th }} \%$ tile male were assigned as the selection criteria of test subjects. The mean and standard deviation for the six primary dimensions of 10 test subjects in this study are also listed in Table 3.

Table 3. Ranges for selection and mean of primary dimensions for test subjects

\begin{tabular}{|c|c|c|}
\hline Body dimension & $\begin{array}{c}\text { Selection } \\
\text { range }\end{array}$ & $\begin{array}{c}\text { Mean }(\mathrm{SD}) \text { of } \\
\text { test subjects }\end{array}$ \\
\hline Weight $(\mathrm{kg})$ & $81.5-89.9$ & $85.9(2.43)$ \\
\hline Height $(\mathrm{m})$ & $1.759-1.799$ & $1.780(0.013)$ \\
\hline Hip Height $(\mathrm{m})$ & $0.870-0.925$ & $0.898(0.018)$ \\
\hline
\end{tabular}




\begin{tabular}{|c|c|c|}
\hline Back Waist Length(m) & $0.476-0.548$ & $0.527(0.013)$ \\
\hline Bust Girth $(\mathrm{m})$ & $1.052-1.170$ & $1.067(0.015)$ \\
\hline Hip Girth $(\mathrm{m})$ & $1.000-1.080$ & $1.034(0.026)$ \\
\hline
\end{tabular}

Both standing and sitting postures of all subjects are scanned in three dimensions, and 32 body dimensions of each subject are digitally measured for the estimation of dynamic properties of 15 body segments at the GEBOD calculation [Cheng 97]. Approval to conduct testing in this study with human subjects was granted by the Pusan National University Institutional Review Board (IRB, PNU IRB/2015_30_HR).

All test subjects hold a driving posture as sitting on the wood seat engraved with the skin shape of HPM-II machine (SAE J4002) which is designed to minimize the slip on the seat during the excitation. The three translational degree of freedom exciter machine (IMV i220) was used for the test. The typical sitting posture on the exciter and the wood seat are shown in Fig. 7.

The test subjects were exposed to the discrete sinusoidal vibrations in uncoupled three translational directions. Three frequencies, $3 \mathrm{~Hz}, 5 \mathrm{~Hz}$, and $10 \mathrm{~Hz}$, at two amplitudes, $0.2 \mathrm{~g}$ and $0.4 \mathrm{~g}$ (c.f., $0.1 \mathrm{~g}$ and $0.2 \mathrm{~g}$ for $3 \mathrm{~Hz}$ excitation), were respectively applied to each of the three directions, fore/aft $(\mathrm{X})$, lateral $(\mathrm{Y})$, and vertical $(\mathrm{Z})$. The test subjects were exposed to the excitations in two
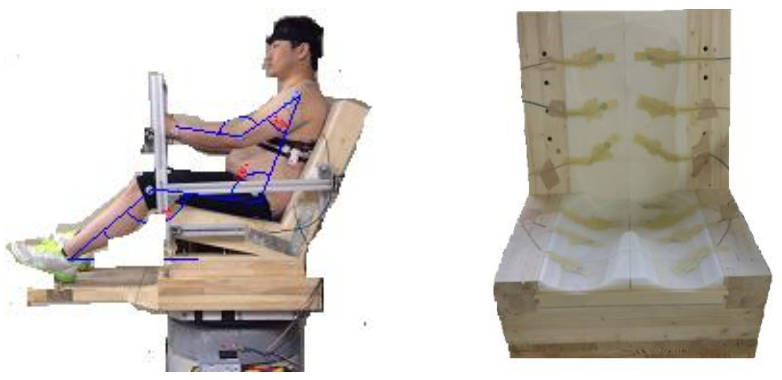

Figure 7. Typical sitting posture of test subject (left) and wood seat engraved with skin shape of HPM-II machine (SAE J4002) (right)

conscious muscle conditions of being relaxed and tensed. In the relaxed muscle condition, the test subjects were requested to strain against the gravity and the excitation just enough to sustain the initial sitting posture. In the tensed muscle condition, the test subjects were instead asked to fully brace their limbs to maximize the resistance against the excitation. There were a total of 36 cases in this excitation test, 3 excitation directions $\mathrm{X}$ 3 frequencies X 2 amplitudes X 2 muscle condition. The body segmental accelerations were measured in three directions at the forehead, chest and two thighs, specifically on the anterior side of the mid femur. The vibration was monitored by the accelerometer (Kistler 8310B) placed on the seat buck platform for a feedback control of the input signal by using NI-PXI8187 controller and Labview software to maintain the frequency and amplitude of the target excitation. The excitation of each vibration case was applied for 20 seconds with a random order. The data of 16 seconds record were just used in the analysis by excluding the first and the last transient 2 seconds.

The frequency analysis of measured body regional acceleration signals was performed by taking Fast Fourier Transformation (FFT) with 99\% overlap and 2second unit time. The $1^{\text {st }}$ peak head acceleration of 6 representative subset cases are listed in Table 4.

Table 4. $1^{\text {st }}$ peak head acceleration of 6 representative subset cases.

\begin{tabular}{|l|l|l|l|l|}
\hline \multirow{2}{*}{ Excitation cases* } & \multicolumn{3}{c|}{ Head acc. $(\mathrm{SD}),\left(\mathrm{m} / \mathrm{s}^{2}\right)$} \\
\cline { 3 - 5 }$\#$ \#1 & X_5Hz_0.2g_R & $\begin{array}{l}0.985 \\
( \pm 24 \%)\end{array}$ & $\begin{array}{l}0.270 \\
( \pm 59 \%)\end{array}$ & $\begin{array}{l}2.100 \\
( \pm 48 \%)\end{array}$ \\
\hline \multirow{2}{*}{$\# 2$} & Y_5Hz_0.2g_R & $\begin{array}{l}0.090 \\
( \pm 73 \%)\end{array}$ & $\begin{array}{l}0.254 \\
( \pm 63 \%)\end{array}$ & $\begin{array}{l}0.153 \\
( \pm 81 \%)\end{array}$ \\
\hline \multirow{2}{*}{$\# 3$} & Z_Hz_0.2g_R & $\begin{array}{l}1.338 \\
( \pm 24 \%)\end{array}$ & $\begin{array}{l}0.311 \\
( \pm 63 \%)\end{array}$ & $\begin{array}{l}2.625 \\
( \pm 53 \%)\end{array}$ \\
\hline \multirow{2}{*}{$\# 4$} & \multirow{2}{*}{ Z_5Hz_0.4g_R } & $\begin{array}{l}2.335 \\
( \pm 26 \%)\end{array}$ & $\begin{array}{l}0.582 \\
( \pm 58 \%)\end{array}$ & $\begin{array}{l}6.259 \\
( \pm 37 \%)\end{array}$ \\
\hline \multirow{2}{*}{$\# 5$} & Z_10Hz_0.2g_R & $\begin{array}{l}1.041 \\
( \pm 32 \%)\end{array}$ & $\begin{array}{l}0.199 \\
( \pm 51 \%)\end{array}$ & $\begin{array}{l}1.384 \\
( \pm 74 \%)\end{array}$ \\
\hline \multirow{2}{*}{$\# 6$} & X_5Hz_0.2g_T & $\begin{array}{l}0.934 \\
( \pm 44 \%)\end{array}$ & $\begin{array}{l}0.379 \\
( \pm 74 \%)\end{array}$ & $\begin{array}{l}3.761 \\
( \pm 39 \%)\end{array}$ \\
\hline
\end{tabular}

\subsection{Exciting vibration simulation with virtual human body model}

Using the 3D FE version of the virtual human body model described in Section 2, the vibration response to excitation was simulated in the following two steps:

Step \#1: Quasi-static sitting phase by gravity loading;

Step \#2: Dynamic excitation phase by discrete sinusoidal loadings.

The gravity driven sitting phase at step \#1 simulates the equilibrium state of the virtual human whole body model in a driving posture. The driver at tensed muscle condition braces articulated joints at upper and lower limbs [Choi 2005]. This bracing behavior at the tensed muscle condition is reproduced by increasing the level of active joint torques. The change of initial sitting posture at tensed muscle condition from the relaxed, especially the slightly more extended elbow joint and tucked-in chin is noticeably shown in Fig. 8. The effect of bracing in the sitting posture on pressure distribution is shown in Fig, 9. The contact area to the seat back at the tensed posture shifts to the upper dorsal back while the contact area in buttock to seat cushion remains 
similar to the relaxed muscle condition. The simulation time for relaxed and tensed initial postures are respectively 1,500 milliseconds and 2,000 millisecond.

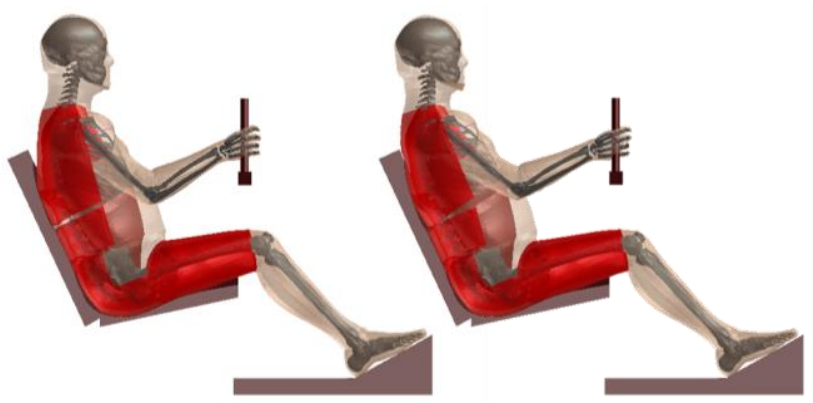

Figure 8. Comparison of simulated initial sitting posture between relaxed (left) and tensed (right) muscle conditions (3D FE model).
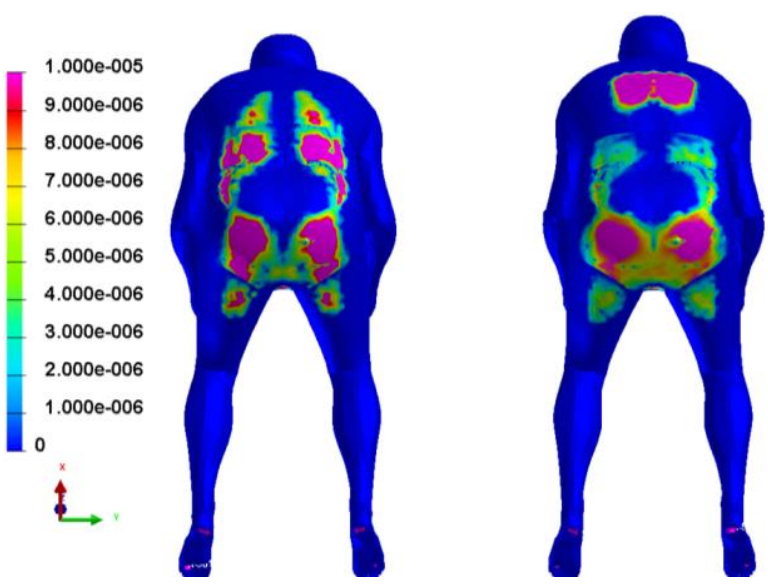

Figure 9. Comparison of simulated sitting pressure distribution between relaxed (left) and tensed (right) muscle conditions (3D FE model).

In Step \#2, a discrete sinusoidal excitation loading is applied for additional 4,000 milliseconds to the equilibrated sitting virtual driver model. The same 3D FE model used for Step \#1 is also utilized to calculate 6dof kinematic outcomes at the COG point of the lower trunk, i.e., time profiles of 3 translational and 3 rotational displacements. This vibration response at the lower trunk body segment is further used as an input signal of the 1D lumped network model (and the 3D FE model without deformable flesh layer) for the calibration process of intrinsic and extrinsic modeling parameters, which is to be described in detail at Section 3.3. Assuming the negligible effect of intrinsic and extrinsic parameters on the kinematics of the lower trunk body segment which is right top of the seat cushion but more to the upper body and the head, the use of the 1D model for the calibration process is far more efficient than the equivalent 3D FE model in terms of the computation time.

\subsection{Calibration of modeling parameters}

Two kinds of modeling parameters, intrinsic and extrinsic variables which are, respectively, independent and dependent on external loadings, are calibrated as in the process shown in Fig. 10. The most important steps in the calibration process are preliminary and decisive optimizations. Both intrinsic and extrinsic parameters are design variables in the preliminary optimization but only extrinsic parameters in the decisive optimization. At the decisive optimization process, the intrinsic parameters adopted from case \#4, the best matching case at the preliminary optimization among 6 loading cases, are used for all cases since they are supposedly independent on external loadings, the excitation direction, frequency, and amplitude. As described in Section 2.2, the mechanical characteristics of tied springs for wobbling masses belong to the intrinsic parameters. The discrete damping values in the kinematic joint element are separately assigned to relaxed (cases \#1-5 in Table 4) and tensed (case\#6) muscle conditions, which represent the level of bracing (co-contraction). The three gain terms at PID controllers for the active joint torque in Section 2.3 fall into the list of extrinsic parameters.

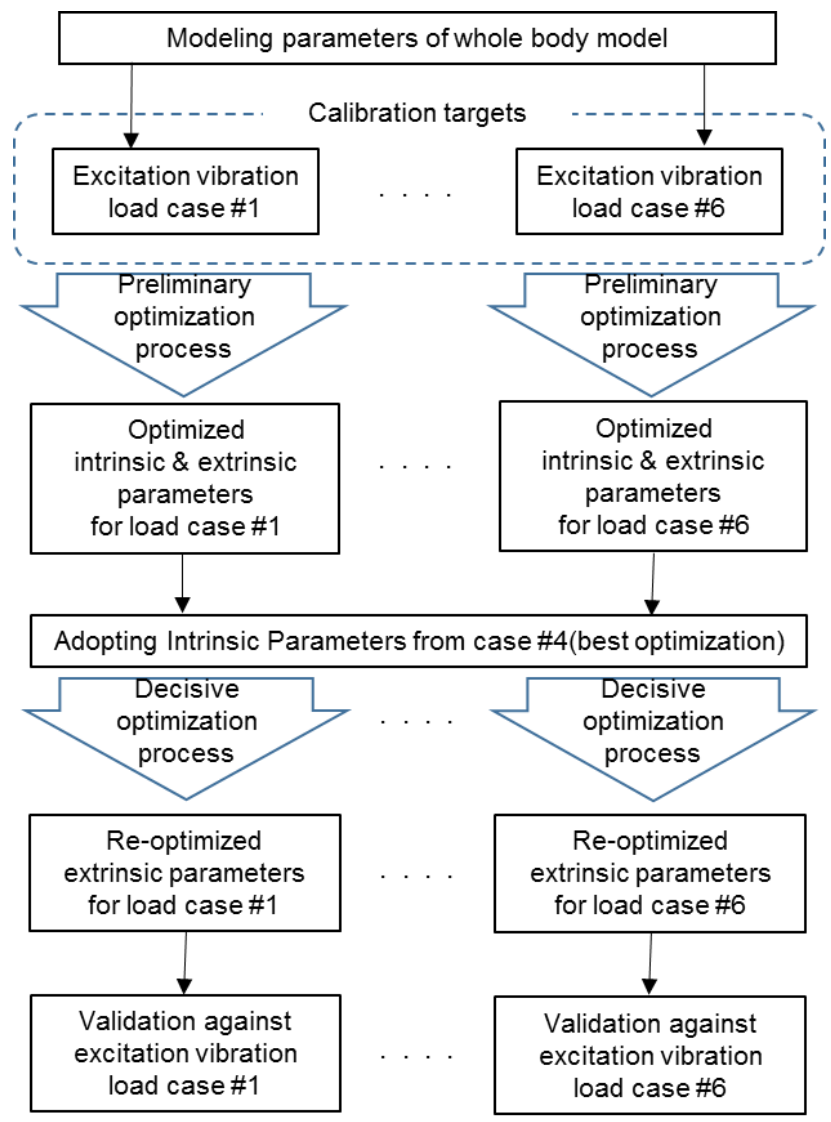

Figure 10. Calibration process for model parameters.

\subsection{Optimization process}

The results from two optimizations in the calibration process in Fig. 10 is listed in Tables 5 and 6. The Genetic Algorithm (GA) at PAM-OPT (www.esi-group.com) is adopted to optimize design variables, given by the intrinsic and extrinsic modeling parameters. The objective function is defined as the following equation; 


$$
\begin{aligned}
\text { Obj. function }= & \left(\left(a_{x_{\text {sim }}}-a_{x_{\text {test }}}\right) / a_{x_{\text {test }}}\right)^{2}+ \\
& \left(\left(a_{y_{\text {sim }}}-a_{y_{\text {test }}}\right) / a_{y_{\text {test }}}\right)^{2}+ \\
& \left(\left(a_{z_{\text {sim }}}-a_{z_{\text {test }}}\right) / a_{z_{\text {test }}}\right)^{2}+ \\
& 0.1 *\left(\max \left(\theta_{c 0-c 1 t}\right) / 1.5\right)^{2}
\end{aligned}
$$

Where,

$a_{i_{s i m}}: 1^{\text {st }}$ peak FFT acceleration in $i$ direction from simulation.

$a_{i_{\text {test }}}: 1^{\text {st }}$ peak FFT acceleration in $i$ direction from test

$\theta_{c 0-c 1 t}$ : Rotation angle of C0_C1 (head-neck) joint in $t$-direction (yawing).

Each iteration (generation) in the GA optimization has a number of 30 points (populations). As an exception, case \#2 Y_5Hz_0.2g_R has 90 populations, three times more than other cases just for the decisive optimization process. The termination criteria is satisfying one the following two conditions;

\#1 Objective function value becomes less than 0.1

\#2 No change in objective function values for last 5 iterations

The objective function values in Table 5 for the preliminary optimization result is smaller than those from the decisive optimization result in Table 6 for all 6 loading cases. This becomes obvious that only extrinsic parameters are optimized as design variables while the uniform intrinsic parameters are assigned as fixed modeling variables in the decisive process.

It is also noted that relatively high objective function values associated with the lateral $\mathrm{Y}$ direction excitation case (\#2 in Table 5 and 6 ) is mainly due to the small baseline effect, i.e., the measured head acceleration is quite smaller than the other excitation directions (see Table 4).

\section{Conclusion}

A virtual human body model is developed to predict the riding comfort design of vehicles. The active response of the human occupant to maintain the upright sitting posture is virtually reproduced by using active joint torques with PID closed loop control. Both 1D lumped network (Modelica) and 3D mesh based (Finite Element) solutions are adopted to model the multibody system architecture of human body. The characteristics of virtual human body model is verified and validated against the excitation test with human subjects.

\section{Future Study}

The virtual human body model will be further validated against the subject test of angular excitations such as rolling and pitching which was performed with 6dof exciter [Choi 2017(2, 3)]. Also a riding comfort index based on ergonomic criteria is under development. Assuming the occupant is trying to develop active joint torques to maintain the upright sitting posture against external perturbations, the total amount of skeletal muscle energy together with body regional transfer function could be a quantitative and objective tool for the assessment of seat, suspension system, and chassis designs in the dynamic performance of vehicle. 
Table 5. Result from the preliminary optimization process in Fig. 10

\begin{tabular}{|c|c|c|c|c|c|c|c|c|c|c|c|c|c|}
\hline \multirow{3}{*}{\multicolumn{2}{|c|}{ Excitation cases* }} & \multicolumn{9}{|c|}{ Preliminary Optimization $1^{\text {st }}$ Peak Head acceleration $(g)$} & \multirow{3}{*}{$\begin{array}{l}\text { Obj. } \\
\text { func. } \\
\text { Value }\end{array}$} & \multirow{3}{*}{$\begin{array}{l}\text { Iter. } \\
\text { No. }\end{array}$} & \multirow{3}{*}{$\begin{array}{l}\text { Iter. } \\
\text { Term }\end{array}$} \\
\hline & & \multicolumn{3}{|c|}{$X$} & \multicolumn{3}{|c|}{$Y$} & \multicolumn{3}{|c|}{$Z$} & & & \\
\hline & & Sim & $\begin{array}{l}\text { Test } \\
(S D)\end{array}$ & $\%$ err. & Sim & $\begin{array}{l}\text { Test } \\
(S D)\end{array}$ & $\%$ err. & Sim & $\begin{array}{l}\text { Test } \\
(S D)\end{array}$ & $\%$ err. & & & \\
\hline$\# 1$ & X_5Hz_0.2g_R & 0.101 & $\begin{array}{l}0.100 \\
( \pm 24 \%) \\
\end{array}$ & $1 \%$ & 0.026 & $\begin{array}{l}0.028 \\
( \pm 59 \%) \\
\end{array}$ & $-6 \%$ & 0.259 & $\begin{array}{l}0.214 \\
( \pm 48 \%) \\
\end{array}$ & $21 \%$ & 0.099 & 12 & $\# 1$ \\
\hline$\# 2$ & Y_5Hz_0.2g_R & 0.006 & $\begin{array}{l}0.009 \\
( \pm 73 \%)\end{array}$ & $-29 \%$ & 0.044 & $\begin{array}{l}0.026 \\
( \pm 63 \%)\end{array}$ & $68 \%$ & 0.008 & $\begin{array}{l}0.016 \\
( \pm 81 \%)\end{array}$ & $-51 \%$ & 0.896 & 15 & $\# 2$ \\
\hline \#3 & Z_5Hz_0.2g_R & 0.112 & $\begin{array}{l}0.136 \\
( \pm 24 \%) \\
\end{array}$ & $-18 \%$ & 0.034 & $\begin{array}{l}0.032 \\
( \pm 63 \%) \\
\end{array}$ & $7 \%$ & 0.272 & $\begin{array}{l}0.268 \\
( \pm 53 \%) \\
\end{array}$ & $2 \%$ & 0.059 & 7 & \#1 \\
\hline \#4 & Z_5Hz_0.4g_R & 0.225 & $\begin{array}{l}0.238 \\
( \pm 26 \%)\end{array}$ & $-5 \%$ & 0.063 & $\begin{array}{l}0.059 \\
( \pm 58 \%) \\
\end{array}$ & $6 \%$ & 0.564 & $\begin{array}{l}0.638 \\
( \pm 37 \%)\end{array}$ & $-12 \%$ & 0.040 & 11 & $\# 1$ \\
\hline \#5 & Z_10Hz_0.2g_R & 0.119 & $\begin{array}{l}0.106 \\
( \pm 32 \%)\end{array}$ & $12 \%$ & 0.013 & $\begin{array}{l}0.020 \\
( \pm 51 \%) \\
\end{array}$ & $-36 \%$ & 0.212 & $\begin{array}{l}0.141 \\
( \pm 74 \%)\end{array}$ & $51 \%$ & 0.414 & 25 & $\# 2$ \\
\hline \#6 & X_5Hz_0.2g_T & 0.115 & $\begin{array}{l}0.095 \\
( \pm 44 \%)\end{array}$ & $21 \%$ & 0.040 & $\begin{array}{l}0.039 \\
( \pm 74 \%)\end{array}$ & $3 \%$ & 0.233 & $\begin{array}{l}0.383 \\
( \pm 39 \%)\end{array}$ & $-39 \%$ & 0.201 & 20 & $\# 2$ \\
\hline
\end{tabular}

*: excitation direction_frequency_amplitude_muscle condition

Table 6. Result from the decisive optimization process in Fig. 10

\begin{tabular}{|c|c|c|c|c|c|c|c|c|c|c|c|c|c|}
\hline \multirow{3}{*}{\multicolumn{2}{|c|}{ Excitation cases* }} & \multicolumn{9}{|c|}{ Decisive Optimization $1^{\text {st }}$ Peak Head acceleration $(g)$} & \multirow{4}{*}{$\begin{array}{c}\text { Obj. } \\
\text { func. } \\
\text { Value }\end{array}$} & \multirow{4}{*}{$\begin{array}{c}\text { Iter. } \\
\text { No. } \\
15\end{array}$} & \multirow{4}{*}{$\begin{array}{l}\text { Iter } \\
\text { stop } \\
\# 2\end{array}$} \\
\hline & & \multicolumn{3}{|c|}{$X$} & \multicolumn{3}{|c|}{$Y$} & \multicolumn{3}{|c|}{$Z$} & & & \\
\hline & & \multirow{2}{*}{$\begin{array}{c}\text { Sim } \\
0.199\end{array}$} & \multirow{2}{*}{$\begin{array}{c}\begin{array}{c}\text { Test } \\
(S D)\end{array} \\
0.100 \\
( \pm 24 \%)\end{array}$} & \multirow{2}{*}{$\frac{\% \text { err. }}{99 \%}$} & \multirow{2}{*}{\begin{tabular}{c|} 
Sim \\
0.033
\end{tabular}} & \multirow{2}{*}{$\begin{array}{c}\begin{array}{c}\text { Test } \\
(S D)\end{array} \\
0.028 \\
( \pm 59 \%)\end{array}$} & \multirow{2}{*}{$\frac{\% \text { err. }}{17 \%}$} & \multirow{2}{*}{\begin{tabular}{c|} 
Sim \\
0.049
\end{tabular}} & \multirow{2}{*}{\begin{tabular}{|c|}
$\begin{array}{c}\text { Test } \\
(S D)\end{array}$ \\
0.214 \\
$( \pm 48 \%)$ \\
\end{tabular}} & \multirow{2}{*}{$\begin{array}{l}\% \text { err. } \\
-77 \%\end{array}$} & & & \\
\hline$\# 1$ & X_5Hz_0.2g_R & & & & & & & & & & & & \\
\hline$\# 2$ & Y_5Hz_0.2g_R & 0.025 & $\begin{array}{l}0.009 \\
( \pm 73 \%) \\
\end{array}$ & $177 \%$ & 0.118 & $\begin{array}{l}0.026 \\
( \pm 63 \%)\end{array}$ & $354 \%$ & 0.037 & $\begin{array}{l}0.016 \\
( \pm 81 \%) \\
\end{array}$ & $130 \%$ & 17.58 & 29 & $\# 2$ \\
\hline \#3 & Z_5Hz_0.2g_R & 0.104 & $\begin{array}{l}0.136 \\
( \pm 24 \%) \\
\end{array}$ & $-24 \%$ & 0.034 & $\begin{array}{l}0.032 \\
( \pm 63 \%) \\
\end{array}$ & $6 \%$ & 0.258 & $\begin{array}{l}0.268 \\
( \pm 53 \%) \\
\end{array}$ & $-4 \%$ & 0.126 & 12 & $\# 2$ \\
\hline \#4 & Z_5Hz_0.4g_R & 0.225 & $\begin{array}{l}0.238 \\
( \pm 26 \%) \\
\end{array}$ & $-5 \%$ & 0.063 & $\begin{array}{l}0.059 \\
( \pm 58 \%) \\
\end{array}$ & $6 \%$ & 0.564 & $\begin{array}{l}0.638 \\
( \pm 37 \%) \\
\end{array}$ & $-12 \%$ & 0.040 & 7 & $\# 1$ \\
\hline$\# 5$ & Z_10Hz_0.2g_R & 0.153 & $\begin{array}{l}0.106 \\
( \pm 32 \%) \\
\end{array}$ & $44 \%$ & 0.025 & $\begin{array}{l}0.020 \\
( \pm 51 \%)\end{array}$ & $25 \%$ & 0.345 & $\begin{array}{l}0.141 \\
( \pm 74 \%)\end{array}$ & $144 \%$ & 2.349 & 18 & $\# 2$ \\
\hline \#6 & X_5Hz_0.2g_T & 0.104 & $\begin{array}{l}0.095 \\
( \pm 44 \%)\end{array}$ & $9 \%$ & 0.039 & $\begin{array}{l}0.039 \\
( \pm 74 \%)\end{array}$ & $-1 \%$ & 0.237 & $\begin{array}{l}0.383 \\
( \pm 39 \%) \\
\end{array}$ & $-38 \%$ & 0.167 & 14 & $\# 2$ \\
\hline
\end{tabular}

*: excitation direction_frequency_amplitude_muscle condition

\section{References}

H. Cheng, L. Obergefell and A. Rizer, The development of the GEBOD program, Biomedical Engineering Conference, Proceedings of the 1996 Fifteenth Southern, 1996.

H. Y. Choi, S.J. Sah, B. Lee, H.S. Cho, S.J. Kang, M.S. Mun, I. Lee, J, Lee, Experimental and numerical studies of muscular activations of bracing occupant. Proc. of Enhanced Safety of Vehicle, Washington D.C. USA, 2005

H.Y. Choi, K. Kim, C. Kim, S. Sah, S. Kim, S. Hwang, K. Lee, J. Pyun, N. Montmayeur, I. Lee, Challenge of Lumbar Support Design Using Human Body Models. SAE Int. J. Passeng. Cars - Mech. Syst. 1(1), 1078-1084, 2009

H.Y. Choi, M. Han, W. Lee, Active Elbow Joint Model. The First Japanese Modelica Conference, 2016

H.Y. Choi, M. Han, J. Park, K. Yang, Air ride seat for Heavy Duty Vehicle. 12th International Modelica Conference, submitted, 2017

H.Y. Choi, M. Han, A. Hirao, H. Matsuoka, Occupant kinematics at vibration excitations: Part I Pure rolling and pitching vibrations. In preparation, 2017
H.Y. Choi, M. Han, A. Hirao, H. Matsuoka, Occupant kinematics at vibration excitations: Part II Real road vibrations. In preparation, 2017

M. Han, H.Y. Choi, Elbow joint model with active muscle force, Journal of Mechanical Science and Technology 30/12 5847 5853, 2016

S. Kim, S. Hwang, K. Lee, J. Pyun, H.Y. Choi, K. Kim, S. Sah, N. Montmayeur, New Anthropometry of Human Body Models for Riding Comfort Simulation. SAE Technical Paper 2007-01-2457, 2007

N. Montmayeur, C. Marca, E. Haug, H.Y. Choi, S. Sah, Experimental and Numerical Analyses of Seating Pressure Distribution Patterns. SAE Technical Paper 2005-01-2703, 2005

K. Yamada, H. Motojima, Y. Kitagawa, T. Yasuki, Investigation of relations between occupant kinematics and supporting by the seat in lane change maneuvers. (In Japanese) Proceedings of JSAE spring conference, No.3816, pp.941-946, 2016 